CARPATHIAN JOURNAL OF FOOD SCIENCE AND TECHNOLOGY

journal homepage: http://chimie-biologie.ubm.ro/carpathian_journal/index.html

\title{
COMPARISON OF TITULOMETRIC AND SPECTROPHOTOMETRIC APPROACHES TOWARDS THE DETERMINATION OF TOTAL SOLUBLE AND INSOLUBLE CARBOHYDRATES IN FOODSTUFF
}

\author{
Eduardo Ramirez Asquieri ${ }^{1 *}$, Aline Gomes de Moura e Silva ${ }^{1}$, Dianiny de Cássia Sousa Mendes ${ }^{2}$, \\ Rayssa Dias Batista ${ }^{2}$ \\ ${ }^{1}$ Faculty of Pharmacy, Federal University of Goias, 74605-170, Goiania - GO, Brazil \\ ${ }^{2}$ School of Agronomy, Federal University of Goias, 74690-900,Goiania-GO, Brazil \\ *asquieri@gmail.com
}

https://doi.org/10.34302/crpjfst/2019.11.3.6

\begin{tabular}{ll}
\hline Article history: & ABSTRACT \\
Received: & Total sugars and carbohydrates can be determined in foodstuff through \\
2 April 2019 & several methods whose analytic principle may significantly differ. In view \\
Accepted: & of this, the aim of this study was to evaluate the use of titrimetric and \\
28 July 2019 & spectrophotometric methods to quantify soluble sugars and total \\
Keywords: & carbohydrates in foods. Therefore, DNS, Somogyi-Nelson, Lane-Eynon, \\
Flour; & and Luff-Schoorl methods were used in the determination of total, reducing, \\
Nectar; & and non-reducing sugars in three nectar-based products and soft drinks. \\
Quantification; & Moreover, the analysis results of total carbohydrates were henceforth used \\
Soda. & to establish a comparison between the findings of wheat bran, cassava flour \\
& and canjica, which were assayed using Phenol-sulfuric and Anthrone \\
& methods. Results showcased that some samples presented different results \\
& according to the method therein used, what suggests the dependency of the \\
findings to the analytical principle of the method. Thence, a deeper & understanding of methodology might enhance results reproducibility \\
& regarding foodstuff analysis.
\end{tabular}

\section{Introduction}

Carbohydrates are chemical compounds whose structural diversity renders their segregation in several classes. Amongst these classes are simple sugars, which encompass monosaccharides and oligosaccharides, as well as those with a more complex structure, such as polysaccharides including starch, cellulose, hemicellulose, gums, and pectins. When total sugars in foodstuff are concerned, only metabolically active monosaccharides and oligosaccharides are considered, including glucose, fructose, and sucrose (BeMiller, 2019).

The demand for low-sugar foods has been steadily increasing in order to minimize the adverse health effects caused by high sugar intake (Başkan et al., 2016). The concentration of easily digestible carbohydrates in food is controlled in some instances by Brazilian Legislation. Regarding products under law monitoring, nectars pose as remarkable examples. These products are unfermented drinks obtained through dilution of fruit pulp in sweetened drinking water, and legislation recommends a minimum of $7 \%$ of total sugars for guava, mango and peach nectars (Brazil, 2003). Other noteworthy products are soft drinks, which are obtained by the dissolution of juice or vegetal extract in sparkling water. Albeit legislation specifies total sugars levels in nectars, soft drinks do not present minimum or maximum 
amount of added sugars defined by any Brazilian law (Brazil, 2009).

The determination of sugars is common in carbohydrate research and the importance of quantifying total sugars and / or total carbohydrates is related to several instances of food quality control, namely: clear and informative labeling; nutritional information; fruit ripening indication; adequate fermentative control; jam-based products control; presence of adulterants, amongst others.

The concentration of carbohydrates or sugars is determinable in foodstuff either through titration, gravimetry, spectrophotometry or chromatography. In addition to quantifying, chromatographic methods also identify sugars which are present in the sample. Amongst the most common chromatographic techniques are layer chromatography, gas chromatography (GC), and high-performance liquid chromatography (HPLC). HPLC and GC can be coupled to nuclear magnetic resonance (NMR) or mass spectrometry (MS) in order to enable the identification of the chemical structure of the eluted chemical compounds (Koh et al., 2018).

Regarding titrimetric methods, LaneEynon and Luff-Schoorl are based on the reaction between reducing sugars and alkaline solution of copper sulphate, with a subsequent reduction of cupric copper to cuprous oxide. In the Luff-Schoorl method, $\mathrm{Cu}^{2+}$ ions which had not been reduced are determined iodometrically, while the reduced copper is determined in Lane-Eynon (Sá et al., 2018). Furthermore, total sugars are thence determined by converting nonreducing sugars into reducing sugars through acid or enzymatic hydrolysis (Marques et al., 2016; Tavares et al., 2010).

Concerning spectrophotometric approaches, Somogyi-Nelson method relies on the following procedures: reducing sugars are heated in alkaline medium to become enediols, which reduce $\mathrm{Cu}^{2+}$ to $\mathrm{Cu}^{+}$ions. The formed cuprous oxide reduces the arsenicmolybdic reactive to a blue-colored molybdenum oxide (Shao \& Lin, 2018). Furthermore, DNS method is based on the reduction of dinitrosalicylic acid to 3-amino5-nitrosalicylic acid in the presence of reducing sugar and $\mathrm{NaOH}$, while different sugars are reported to produce different intensities in red-brown coloration (Başkan et al., 2016).

Polysaccharides in foodstuff might undergo hydrolysis rendering monosaccharides, which are of utmost importance in total carbohydrate content determination. For this purpose, the following methods were herein applied to determine total carbohydrate content: Anthrone method (Body et al., 2018); phenol-sulfuric method (Dubois et al., 1956; Wang et al., 2017; Le \& Stuckey., 2016).

The samples herein used to compare total carbohydrates determination methods were: wheat bran, canjica corn and cassava flour. Wheat bran is the by-product of the manufacture of wheat flour. Its composition includes insoluble fibers (cellulose and lignin), starch, oligosaccharides and traces of reducing sugars and sucrose (Hemdane et al., 2016). Canjica corn is composed of grains or pieces of canjica corn, which present partial or total absence of the germ, depending on the mechanical or manual (degermination) scarification process (Brazil, 1989). In the carbohydrate fraction of canjica, a great quantity of starch is present, followed by fiber and low soluble sugars. (Strazzi, 2015). Dry cassava flour is the product obtained from healthy cassava roots, duly cleaned, peeled, crushed, grated, grounded, pressed, sieved and dried at the appropriate temperature (Brazil, 2011). Dias and Leonel (2006) characterized cassava flour from different Brazilian states and reported variations in the levels of starch, fiber and soluble sugars. 
The use of titrimetric and spectrophotometric methods is still present in accredited laboratories for the issuance of food quality reports. Moreover, these tests are also reliable for industrial and scientific purposes, being largely used in foodstuff research.

Spectrophotometric methods for total sugar determination are in current use hence their good sensitivity, low cost, easy operation and accessible equipment. Literature also reports colorimetric tests for sugar determination in varied samples, albeit their analytic features are not as remarkable as those of spectrophotometric assays (Başkan et al., 2016).

Due to the different characteristics of each method, and the importance of determining sugar content in foods, the present work aims to compare titration and spectrophotometric methods used in the determination of soluble sugars and total carbohydrates in foods in order to verify their accuracy in the detection of these nutrients.

\section{Materials and methods}

\subsection{Determination of total sugars (total soluble carbohydrates)}

The first stage of this study involved the analysis of reducing sugars, sucrose, and total sugars in three nectar-based products, namely: peach, guava, and mango nectars, as well as three flavors of soft drinks: lemon, guarana, and orange. The samples were purchased in a supermarket located in Goiania, Goias, Brazil. The soft drinks were degassed before analysis. Solution of known concentration of analytic-grade glucose, fructose and sucrose were used as controls. For determination of total sugars was applied the methods Lane-Eynon (Fehling), LuffSchoorl, DNS and Somogyi - Nelson.

The overall procedure was divided in two steps: quantification of sugars pre-hydrolysis and post-hydrolysis. The calculation of dilutions was based on the linear range of the methods. Therefore, from 0.02 to $0.12 \mathrm{mg}$ of sugar was established for the SomogyiNelson according to the methodology described in this study. Regarding DNS, linear range was from 0.10 to $0.54 \mathrm{mg}$, while Luff-Schoorl was up to $50 \mathrm{mg}$, and LaneEynon up to $100 \mathrm{mg}$. Another possibility to verify whether the dilution is correct in the case of spectrophotometric methods is to observe whether the absorbances of the samples are close to the reading range of the absorbances of the standard curve.

Whenever possible, it is suggested to proceed with only one (1) dilution to remove aliquots from the sample; spectrophotometric methods are generally more demanding regarding sample clarity, therefore, a filtration was performed to remove solid particles after dilution.

It is important to highlight that colored or turbid samples may interfere with turning point verification or spectrophotometric readings. Thus, they must be clarified with the use of activated carbon or precipitated with lead acetate. Acetate forms insoluble complexes with interfering substances, which may be removed through filtration or centrifugation (McClements, 2014). The methods used are described below:

\section{- Lane-Eynon (Fehling)}

It was used an adaptation of the method described by Lane \& Eynon (1934) and Fehling's solution was standardized using $1 \%$ glucose solution. Therefore, the method comprises as it follows: addition of $10 \mathrm{~mL}$ of Fehling A solution, $10 \mathrm{~mL}$ of Fehling B solution, and $40 \mathrm{~mL}$ of water in erlenmeyer followed by boiling of the mixture in a magnetic stirrer under heating (Hotlab, Nalgon). Addition and titration of methylene blue indicator in sample solution until red precipitate appeared. Sucrose after acid hydrolysis is determined considering the relation described by Meade (1967): addition of $10 \mathrm{~mL}$ of $\mathrm{HCl}$ per $10 \mathrm{~mL}$ of solution with $17^{\circ}$ Brix for hydrolysis and $20 \mathrm{~mL}$ of $6 \mathrm{~N}$ 
$\mathrm{NaOH}$ for neutralization. A ten-minute water bath (Dubnoff NT-232, Novatecnica) at $60^{\circ} \mathrm{C}$ followed the acid addition, and was neutralized with $\mathrm{NaOH} 6 \mathrm{~N}$, cooled, and the volume re-filled. Calculation of sucrose content occurred through the difference between reducing sugars content pre and post hydrolysis with a conversion factor of 0.95 . The content of total sugars is the sum of reducing sugars and sucrose.

Lane-Eynon method requires constant boiling during titration to prevent cuprous oxide (reddish-colored) from being oxidized by the oxygen present in the air and returning to the cupric oxide (blue color) (Tavares et al., 2010). In addition, considering the necessity of heating, titration should continue up to three minutes in order to avoid the degradation of sugars from prolonged exposure to heating.

\section{- Luff-Schoorl}

The samples were analyzed according to Matissek et al. (1998) followed by a blank assay preparation with $25 \mathrm{~mL}$ of LuffSchoorl reagent, $25 \mathrm{~mL}$ of water, $10 \mathrm{~mL}$ of $30 \%$ potassium iodide, $25 \mathrm{~mL}$ of $6 \mathrm{~N}$ sulfuric acid solution, and $0.5 \mathrm{~mL}$ of $1 \%$ starch. The mix was titrated with $0.1 \mathrm{~N}$ sodium thiosulfate up to white coloration. The samples were then added with $25 \mathrm{~mL}$ of LuffSchoorl reagent and $25 \mathrm{~mL}$ of sample. The solution was heated on magnetic stirrer with heating (Hotlab, Nalgon) coupled to reflux, and subjected to 10-minute boiling. Thereafter, the solution was cooled and added with $10 \mathrm{~mL}$ of $30 \%$ potassium iodide, $25 \mathrm{~mL}$ of $6 \mathrm{~N}$ sulfuric acid solution and 0.5 $\mathrm{mL}$ of $1 \%$ starch. Thereafter, the solution was titrated with $0.1 \mathrm{~N}$ sodium thiosulfate to white coloration. Calculation of the difference in blank volume and titrated sample volume was followed by the insertion of the amount of reducing sugar in $\mathrm{mg}$ in the table cited by Vicente (1994). Sucrose was determined according to Meade (1967) after acid hydrolysis and calculated by the difference between the reducing sugars content pre and post hydrolysis using a conversion factor of 0.95 . The content of total sugars is the sum of reducing sugars and sucrose.

For most of Luff-Schoorl method application cases, the calculation of the results should involve interpolation hence the values relating to the titrated volume and to the amount of sugar are tabulated.

\section{- DNS}

The method described by Miller (1959) was proceeded with an adaptation and was prepared using a standard curve with glucose concentrations ranging from 100 to $540 \mu \mathrm{g}$. Sample dilution was followed by aliquots of 0.3 to $1.0 \mathrm{~mL}$ pipetted into test tubes, addition of $2.0 \mathrm{~mL}$ of DNS reagent, and volume quenched to $4.2 \mathrm{~mL}$ with water followed by water bath (Dubnoff NT-232, Novatecnica) for six minutes at $100^{\circ} \mathrm{C}$ and cooled in running water. The absorbance at $540 \mathrm{~nm}$ was read in a spectrophotometer (Rayleigh UV-1601 UV-VIS), sucrose was determined after acid hydrolysis according to Meade (1967) and calculated by the difference between the content of reducing sugars pre and post hydrolysis and multiplication by the conversion factor of 0.95 . The content of total sugars was determined by the sum of reducing sugars and sucrose.

\section{- Somogyi-Nelson}

The methodology herein used was adapted from Somogyi (1945) and made use of a standard curve with concentrations ranging from 20 to $120 \mu \mathrm{g}$ from a $0.01 \%$ glucose solution for reducing sugars determination. Thence, $1.2 \mathrm{~mL}$ of water and $1.0 \mathrm{~mL}$ of cupric reagent were added for the reaction and underwent boiling water bath (Dubnoff NT-232, Novatecnica) for 10 minutes. The mix was then cooled in running water and added with $1.0 \mathrm{~mL}$ of arsenicmolybdic reagent and $6.0 \mathrm{~mL}$ of water. Absorbance was read at $510 \mathrm{~nm}$ in a spectrophotometer (Rayleigh UV-1601 UV- 
VIS). Sucrose was determined after acid hydrolysis according to Meade (1967) and calculated by the difference between the content of reducing sugars pre and post hydrolysis followed by multiplication by the conversion factor of 0.95 . Total sugars content is the sum of reducing sugars and sucrose.

\subsection{Determination of total carbohydrates}

At the second stage, total carbohydrate analysis was performed on samples of wheat bran, cassava flour, and canjica, purchased at a supermarket in the city of Goiania, Goias, Brazil. The samples were milled and screened in a 20 mesh sieve before analysis, and to validate the methodologies, solutions of known concentration containing analyticgrade xanthan gum, pectin citric, starch, and sucrose were used as controls.

In the case of foods containing higher proportion of polysaccharides than soluble sugars, it is not advisable to apply the Brix measurement, which led us to seek to know the food composition and proceed with dilution attempts according to the working range of the chosen method.

Notwithstanding, it is recommended to use a single dilution, since the amount of dilutions multiplies the errors. After dilution, the aliquots should be pipetted under agitation considering the samples insolubility in water as well as to avoid the precipitation of carbohydrates. In the case of starch-rich samples, heating in aqueous solution may benefit the dilution process. For samples which are rich in insoluble fibers, heating has no effect, while for wheat bran, sample preparation consisted of sifting the bran (20 mesh sieve), performing the dilution, and pipetting the aliquots under stirring. The following methods were therefore applied:

- Phenol-sulfuric

The analysis described by Dubois et al. (1956) was carried out with a few modifications and proceeded with a curve with glucose concentrations ranging from 10 to $90 \mu \mathrm{g}$. After sample preparation, aliquots of 0.2 to $1.5 \mathrm{~mL}$ were pipetted into test tubes and the volume was filled until $2.0 \mathrm{~mL}$ with $0.8 \mathrm{~mL}$ of $5 \%(\mathrm{w} / \mathrm{w})$ phenol and $5 \mathrm{~mL}$ of sulfuric acid. The tubes were then shaken and left to stand for 30 minutes for further reading in a spectrophotometer (Rayleigh UV-1601 UV-VIS) at $490 \mathrm{~nm}$.

- Anthrone

Methodology adapted from Morris (1948). Standard curve was prepared with glucose concentrations ranging from 50 to $300 \mu \mathrm{g}$. Sample preparation was followed by aliquots of 0.2 to $1.2 \mathrm{~mL}$ and pipetted into test tubes. The volume was thereafter filled until $2.0 \mathrm{~mL}$ with water. $4 \mathrm{~mL}$ of Anthrone reagent was then added to all tubes. The tubes were shaken and allowed to stand for 15 minutes. The absorbance was read in a spectrophotometer (Rayleigh UV-1601 UVVIS) at $620 \mathrm{~nm}$.

\subsection{Statistical analysis}

Statistical analysis was performed with at least two replicates in triplicate. Data of reducing sugars, sucrose and total sugars were subjected to analysis of variance (ANOVA) using the program Statistica version 10.0 followed by Tukey test at 5\%, while total carbohydrates analysis occurred through Student test at 5\%.

\section{Results and discussions}

\subsection{Determination of total sugars}

The control solution revealed a difference in the determination of reducing sugars between the results of Somogyi-Nelson, DNS and Luff-Schoorl (Table 1). In general, all methodologies presented satisfactory results with a maximum deviation of 0.79 . 
Table 1. Total sugars (TS), reducing sugars (RS) and sucrose contents of the control solution and different flavors of nectars

\begin{tabular}{|c|c|c|c|c|c|c|}
\hline Sample & Analysis & DNS & Eynon & Luff & Somogyi & ${ }^{\circ}$ Brix \\
\hline Control & TS & $9.74 \pm 0.79^{\mathrm{a}}$ & $9.85 \pm 0.07^{\mathrm{a}}$ & $9.51 \pm 0.0^{\mathrm{a}}$ & $10.17 \pm 0.51^{\mathrm{a}}$ & 10.0 \\
\hline & RS & $7.65 \pm 0.16^{\mathrm{b}}$ & $7.92 \pm 0.0^{\mathrm{ab}}$ & $7.76 \pm 0.04^{\mathrm{b}}$ & $8.40 \pm 0.18^{\mathrm{a}}$ & \\
\hline & Sucrose & $2.08 \pm 0.63^{\mathrm{a}}$ & $1.93 \pm 0.07^{\mathrm{a}}$ & $1.75 \pm 0.03^{\mathrm{a}}$ & $1.77 \pm 0.33^{\mathrm{a}}$ & \\
\hline Guava & TS & $13.95 \pm 0.33^{\mathrm{a}}$ & $13.08 \pm 0.23^{\mathrm{ab}}$ & $12.38 \pm 0.11^{\mathrm{b}}$ & $12.89 \pm 0.29^{\mathrm{b}}$ & 13.6 \\
\hline & RS & $6.73 \pm 0.06^{\mathrm{a}}$ & $6.01 \pm 0.07^{\mathrm{a}}$ & $6.17 \pm 0.02^{\mathrm{a}}$ & $6.29 \pm 0.37^{\mathrm{a}}$ & \\
\hline & Sucrose & $7.22 \pm 0.40^{\mathrm{a}}$ & $7.07 \pm 0.15^{\mathrm{ab}}$ & $6.22 \pm 0.09^{\mathrm{b}}$ & $6.61 \pm 0.09^{\mathrm{ab}}$ & \\
\hline Mango & TS & $14.55 \pm 0.19^{\mathrm{a}}$ & $13.55 \pm 0.08^{\mathrm{b}}$ & $13.29 \pm 0.31^{\mathrm{b}}$ & $13.59 \pm 0.31^{\mathrm{ab}}$ & 14.8 \\
\hline & RS & $7.79 \pm 0.09^{\mathrm{a}}$ & $7.17 \pm 0.16^{\mathrm{b}}$ & $6.98 \pm 0.09^{\mathrm{b}}$ & $7.80 \pm 0.02^{\mathrm{a}}$ & \\
\hline Peach & Sucrose & $6.76 \pm 0.28^{\mathrm{a}}$ & $6.38 \pm 0.24^{\mathrm{a}}$ & $6.32 \pm 0.21^{\mathrm{a}}$ & $5.80 \pm 0.29^{\mathrm{a}}$ & \\
\hline & TS & $12.12 \pm 0.15^{\mathrm{a}}$ & $11.03 \pm 0.23^{\mathrm{b}}$ & $11.71 \pm 0.01^{\mathrm{ab}}$ & $12.34 \pm 0.38^{\mathrm{a}}$ & 12.0 \\
\hline & RS & $3.87 \pm 0.04^{\mathrm{a}}$ & $3.56 \pm 0.19^{\mathrm{a}}$ & $3.77 \pm 0.01^{\mathrm{a}}$ & $3.92 \pm 0.02^{\mathrm{a}}$ & \\
\hline & Sucrose & $8.25 \pm 0.19^{\mathrm{ab}}$ & $7.48 \pm 0.04^{\mathrm{b}}$ & $7.95 \pm 0.02^{\mathrm{ab}}$ & $8.43 \pm 0.36^{\mathrm{a}}$ & \\
\hline
\end{tabular}

Expressed as mean \pm standard deviation. Different letters on the same line indicate a significant difference $(\mathrm{P} \leq 0.05)$ by the Tukey test at $5 \%$.

Brix measurement was performed to render reference values. ${ }^{\circ}$ Brix establishes the amount of total soluble solids in the sample expressed as percentage (\% w / w); it usually refers to soluble sugars, but may also be atributed to organic acids, minerals, and water-soluble vitamins as well (Dongare et al., 2015); therefore, Brix provides an approximate value of total sugars.

Caldas et al. (2015) conducted comparative experiments between refractometry, phenol-sulfuric method, and liquid chromatography applied to the determination of total sugars in nectar and concentrated grape juice. For these samples, refractometry was adequate to routine measurements of total sugars and presented the lowest variation among the contents, in addition to an easy and simple use.

In the case of guava nectar, the Brazilian legislation recommends the minimum of: $10^{\circ}$ Brix, $7 \%$ of total sugars, and $35 \%$ of pulp (Brazil, 2003) and according to Ishartani et al. (2018), guava has approximately $7 \%$ of soluble sugars, which are largely composed of fructose and glucose as well as a low sucrose amount $(<2 \%)$. However, the nectar is known to be added with sucrose. Therefore, the investigation was proceeded with the quantification of total sugars by reducing sugars and sucrose using the methods indicated for such analysis, namelly: Luff-Schoorl, Lane-Eynon, DNS, and Somogyi-Nelson.

The results of guava nectar indicated no difference between the methodologies for reducing sugars while sucrose had a difference between DNS and Luff-Schoorl values, which led to differences in total sugars between both methods as well.

Concerning mango nectar, Brazilian Ministry of Agriculture established the minimum range of $10^{\circ} \mathrm{Brix}, 7 \%$ for total sugars, and $40 \%$ of pulp (Brazil, 2003). In the study by Dar et al. (2016) mango presents sugar concentrations in descending order, namelly: sucrose, fructose, and glucose, as well as that the aldose content does not exceed $1 \%$ and the analysis of reducing sugars of mango nectar indicated that spectrophotometric methods statistically differ from titrimetric methods; however, sucrose had no difference between the results. Regarding the values of total sugars, DNS showed a difference in relation to titrimetric methods, which in turn did not differ from the Somogyi-Nelson results.

Brazilian legislation states that peach nectar must have at least $10^{\circ}$ Brix, $7 \%$ total sugars, and $40 \%$ fruit pulp (Brazil, 2003). 
The results of sucrose analysis given by Somogyi-Nelson differed from Lane-Eynon. Sucrose content was verified to be practically double than that of reducing sugars, which, in turn, had no statistical difference between the methods herein used. The content of reducing sugars was below the remaining flavors, probably because, according to Saidani et al. (2017), peach presents about $10 \%$ of total sugars, out of which $80 \%$ is sucrose and the remaining is glucose, fructose, and others. Regarding total sugars, the values found by DNS and Somogyi-Nelson presented statistical difference regarding the value obtained by Lane-Eynon method.

Concerning the production of soft drinks, sucrose may be partially or totally replaced with inverted sucrose, fructose or glucose. Minimum or maximum quantities of sugars are not defined in the Brazilian legislation.
Lemon soda should contain at least $2.5 \%$ lemon juice according to the Brazilian legislation (Brazil, 2009). Regarding total sugars determination, Luff-Schoorl differed from spectrophotometric methods (Table 2) while for reducing sugars, the value found by applying the Somogyi-Nelson technique differed from the others. The sucrose contents of the titrimetric methods were similar to each other, but different from the ones of spectrophotometric tests.

Orange soda should contain at least $10 \%$ orange juice, which in turn must have a minimum of $10.5^{\circ}$ Brix according to Brazilian legislation (Brazil, 1998). The different methodologies had no distinguishable results for total sugars, reducing sugars, and sucrose.

Guarana soft drink is produced with at least $20 \mathrm{mg} / 100 \mathrm{~mL}$ of natural guarana extract according to the Brazilian legislation (Brazil, 2009).

Table 2. Total sugars (TS), reducing sugars (RS) and sucrose contents of different flavors of soft drinks

\begin{tabular}{|l|c|c|c|c|c|c|}
\hline Sample & Analysis & DNS & Eynon & Luff & Somogyi & ${ }^{\circ}$ Brix \\
\hline Lemon & TS & $10.30 \pm 0.12^{\mathrm{bc}}$ & $10.60 \pm 0.04^{\mathrm{ab}}$ & $10.74 \pm 0.06^{\mathrm{a}}$ & $10.20 \pm 0.07^{\mathrm{c}}$ & 10.0 \\
\hline & RS & $2.90 \pm 0.0^{\mathrm{b}}$ & $2.60 \pm 0.11^{\mathrm{c}}$ & $2.75 \pm 0.06^{\mathrm{bc}}$ & $3.27 \pm 0.08^{\mathrm{a}}$ & \\
\hline & Sucrose & $7.40 \pm 0.12^{\mathrm{b}}$ & $8.00 \pm 0.14^{\mathrm{a}}$ & $7.99 \pm 0.00^{\mathrm{a}}$ & $6.94 \pm 0.01^{\mathrm{c}}$ & \\
\hline Orange & TS & $10.00 \pm 0.30^{\mathrm{a}}$ & $10.21 \pm 0.14^{\mathrm{a}}$ & $9.84 \pm 0.27^{\mathrm{a}}$ & $9.59 \pm 0.22^{\mathrm{a}}$ & 11.0 \\
\hline & RS & $4.10 \pm 0.04^{\mathrm{a}}$ & $3.82 \pm 0.03^{\mathrm{a}}$ & $3.87 \pm 0.02^{\mathrm{a}}$ & $3.82 \pm 0.19^{\mathrm{a}}$ & \\
\hline & Sucrose & $5.80 \pm 0.26^{\mathrm{a}}$ & $6.39 \pm 0.11^{\mathrm{a}}$ & $5.97 \pm 0.25^{\mathrm{a}}$ & $5.78 \pm 0.03^{\mathrm{a}}$ & \\
\hline Guarana & TS & $8.41 \pm 0.15^{\mathrm{a}}$ & $8.40 \pm 0.05^{\mathrm{a}}$ & $8.40 \pm 0.18^{\mathrm{a}}$ & $8.19 \pm 0.14^{\mathrm{a}}$ & 9.0 \\
\hline & RS & $1.04 \pm 0.01^{\mathrm{a}}$ & $0.95 \pm 0.02^{\mathrm{ab}}$ & $0.91 \pm 0.02^{\mathrm{b}}$ & $0.93 \pm 0.04^{\mathrm{ab}}$ & \\
\hline & Sucrose & $7.37 \pm 0.16^{\mathrm{a}}$ & $7.40 \pm 0.07^{\mathrm{a}}$ & $7.50 \pm 0.16^{\mathrm{a}}$ & $7.26 \pm 0.10^{\mathrm{a}}$ & \\
\hline
\end{tabular}

Expressed as mean \pm standard deviation. Different letters on the same line indicate a significant difference $(\mathrm{P} \leq 0.05)$ by the Tukey test at $5 \%$.

The methods to quantify the total sugars of guarana soft drink did not indicate different results. The content of reducing sugars achieved through the DNS was different from the values obtained through Luff-Schoorl. All methodologies presented similar results for sucrose. Guarana soda presented the lowest reducing sugar content in relation to the remaining assayed flavors.
This fact reflected the sample preparation, especially for the Lane-Eynon technique.

Most of the sugars in guarana soft drink are sucrose, which is an important point to emphasize since knowledge on the food composition benefits the satisfactory progress of the analysis. Therefore, Brix measurement revealed that the three flavors of soft drinks have close Brix degrees, but the 
sucrose content of guarana soft drink is above that of reducing sugars.

In order to calculate the dilution during the stage without hydrolysis, the proportion of reducing and non-reducing sugars was estimated. Considering the presence of small amounts of reducing sugars in guarana soft drink, it did not require dilution to undergo Lane-Eynon method. In order to proceed with the analysis through such method, the preparation of the sample dilution considers that the solution must contain about $1 \mathrm{~g}$ of reducing sugars, a quantity based on the standard solution, which is taken as reference for the calculations. The stage involving hydrolysis uses the Brix value to calculate the dilution as an approximation of the total sugars.

During the execution of the analysis, it was found that the Lane-Eynon method is indicated for samples with amounts of sugars above 1\%; in contrast, the pure sample should be directly titrated (i.e. without dilution), which may lead to higher sample volume expenditure considering repetitions and results accuracy. Despite being an official method, it was recommended to substitute the Lane-Eynon with another more sensitive method at low concentrations in these cases.

In contrast, the Somogyi-Nelson method is adequate to low concentrations, which led us to understand that samples with higher total sugars (> 10\%) should not undergo it, considering its demand for large dilution volumes.

During sucrose hydrolysis process, formation of furfural (in the case of pentoses) or hydroxymethylfurfural (in the case of hexoses) may result from the action of acids and heat. Incorrect hydrolysis (excess acid, heating time) may favor the formation of these compounds; therefore, it is necessary to neutralize the sample after the acid hydrolysis as well. The presence of furfural leads to a lower amount of sugar in relation to the real value, since it has no reducing property and does not react with Fehling or Luff-Schoorl solution. Moreover, an overestimated value is obtained through the DNS method derived from furfural influence on the coloration, and consequently, the absorbance value.

Another important point is that ascorbic acid significantly interferes in the results of reducing sugars and total sugars analysis, either through the Lane-Eynon method or others with the basic principle of oxidationreduction reaction. Therefore, Tavares et al. (2010) proposed an approach to calculate the error for foods with high concentrations of ascorbic acid (above $500 \mathrm{mg} / 100 \mathrm{~g}$ ) and low concentrations of sugars.

Baskan et al. (2016) also emphasize that polyphenols can interfere in the determination of reducing sugars when using colorimetric methods based on redox reactions.

Silva et al. (2003) compared several methods to establish reducing sugars, sucrose, and total sugars in honeys to verify that the results of sucrose and total sugars presented no difference between the applied methods; however, for reducing sugars, the Luff-Schoorl methodologies and MunsonWalker generated lower values.

Demiate et al. (2002) compared the Somogyi-Nelson and Lane-Eynon method with Phenol-sulfuric acid (which is taken as the reference) in the determination of reducing sugars and total sugars of apple juice and soft drinks. The analysis of variance indicated no significant difference between the studied methodologies considering the significance level of $1 \%$.

\subsection{Determination of total carbohydrates}

The methods showed no difference regarding the control solution and the results of total carbohydrates. Moreover, the wheat bran presented no significant difference (Table 3). 
Table 3. Total carbohydrates contents of wheat bran, cassava flour and canjica

\begin{tabular}{|l|c|c|}
\hline Sample & $\begin{array}{c}\text { Phenol- } \\
\text { sulfuric }\end{array}$ & Anthrone \\
\hline Control & $0.53 \pm 0.02^{\text {ns }}$ & $0.51 \pm 0.02^{\text {ns }}$ \\
\hline Wheat bran & $74.5 \pm 1.13^{\text {ns }}$ & $72.4 \pm 2.33^{\text {ns }}$ \\
\hline Cassava flour & $90.6 \pm 0.55^{\mathrm{s}}$ & $83.8 \pm 1.89^{\mathrm{s}}$ \\
\hline Canjica & $76.1 \pm 2.97^{\mathrm{ns}}$ & $77.5 \pm 1.30^{\mathrm{ns}}$ \\
\hline
\end{tabular}

Expressed as mean \pm standard deviation. Averages in the same line do not differ significantly (ns) or differ (s) from each other $(\mathrm{P} \leq 0.05)$.

Regarding cassava flour, Dias \& Leonel (2006) characterized cassava flour from different Brazilian states and reported variations in starch, fiber, and soluble sugars. Indeed, a significant difference appeared in the analysis of total carbohydrates. The application of the Phenol-sulfuric methodology revealed highest content, a value close to the findings of Nepa (2011), $89.2 \%$ of total carbohydrates.

White canjica contains $78.1 \%$ of carbohydrates according to Nepa (2011) and a value close to those rendered through Phenol-sulfuric and Anthrone methods, with no significant difference.

The methods used in this work to analyze total carbohydrates have different linear ranges: Anthrone method quantifies from 0.05 to $0.3 \mathrm{mg}$ of carbohydrates while Phenol-sulfuric technique ranges between 0.01 and $0.09 \mathrm{mg}$.

According to Silva et al. (2003), a major disadvantage of the Phenol-sulfuric method is the use of higher amounts of sulfuric acid. Nevertheless, it is a simple method which generates sensitive and reproducible results. The case of Anthrone method involves the use of sulfuric acid as well, but only in the Anthrone reagent preparation. Nonetheless, it was verified that Anthrone method had greater difficulty regarding the reproducibility of the results.

Total carbohydrates are normally calculated by inference, considering the difficulty of analysis or even that the environmentally hazardous potential of the recommended techniques (Phenol-sulfuric and Anthrone). The calculation by inference can lead to erroneous results hence experimental errors in relation to the methods associated with the determination of other nutrients. Therefore, a direct measure of total carbohydrate content should be carried out upon an expressive content.

Method linear range and food composition have high influence on the results. It is important to observe that the choice of method is associated with the sample type, method working range, cost of equipment and reagents, time of analysis, including time to prepare reagents, sample, and reaction time. It is also worth noticing the issue of chemical residues generation and the determination purpose, either for routine analysis or research.

\section{Conclusions}

The analytical methods were successfully applied in quantitative tests of soluble sugars and total carbohydrates of nectars, soft drinks, wheat bran, cassava flour, and canjica. The spectrophotometric methods are commonly regarded as more accurate than titrimetric. However, the present study showed that no differences were found between most of the results. For the samples which undergone total carbohydrates determination, the analysis through PhenolSulfuric method may render more reproducible results than through Anthrone method.

\section{References}

Başkan, K.S., Tütem, E., Akyüz, E., Özen, S., Apak, R. (2016). Spectrophotometric total reducing sugars assay based on cupric reduction. Talanta, 147, 162-8.

BeMiller, J. N. (2019). Carbohydrate Chemistry for Food Scientists. (3rd ed.). Indiana: AACC International, (Chapter $1)$. 
Body, M. J. A., Jérôme Casas, J., Christidès, J., David Giron, D. (2018). Underestimation of carbohydrates by sugar alcohols in classical anthronebased colorimetric techniques compromises insect metabolic and energetic studies. Journal of Insects as Food and Feed, 1- 8.

Brazil (1989). Normative Instruction No. 109 of February 24, 1989. Standard of identity, quality, presentation and packaging of canjica. Available at: <www.codapar.pr.gov.br/arquivos/File/p df/canjica109_89.pdf >. Accessed on: 01 February 2018.

Brazil (1998). Normative Instruction No. 544 of November 16, 1998. Technical regulation for setting identity and quality standards for refreshment. Available at: <https://www.diariodasleis.com.br/busca /exibelink.php?numlink=223740>. Accessed on: 02 February 2018.

Brazil (2003) Normative Instruction No. 12 of September 4, 2003. General technical regulation for the establishment of general identification and quality for tropical juice. Available at: <www.idec.org.br/pdf/instrucaonormativa-12.pdf $>$. Accessed on: 02 February 2018.

Brazil (2009) Decree $\mathrm{n}^{\circ}$ 6.871, of June 4, 2009. Standard for standardization, classification, registration, inspection, production and inspection of beverages. Available at:〈www.agricultura.gov.br/>. Accessed on: 03 February 2018.

Brazil (2011). Normative Instruction No. 52 de November 7, 2011. Technical Regulation of Cassava Flour. Available at: $<w w w . c o d a p a r . p r . g o v . b r / a r q u i v o s / F i l$ e/pdf/FarinhadeMandiocaIN522011.pdf. Accessed on: 07 February 2018.

Caldas, B.S., Constantino, L.V., Silva, C.H.G.A., Madeira, T.B., Nixdorf, S.L. (2015). Comparative assessment of sugar in concentrated and nectar grape juices by refractometry, spectrophotometry and chromatography. Scientia Chromatographica, 7 (1), 53-63.

Dar, M. S., Oak, P., Chidley, H., Deshpande, A., Giri, A., Gupta, V. (2016). Nutrient and Flavor Content of Mango (Mangifera indica L.) Cultivars: Na Appurtenance to the List of Staple Foods. Nutritional Composition of Fruit Cultivars, 445-467.

Demiate, M., Wosiacki, G., Czelusniak, C., Nogueira, A. (2002). Analysis of total and reducing sugars in foods. A comparative study between colorimetric and titration techniques. Publicatio UEPG - Exact and Soil Sciences, Agrarian Science and Engineering, 8 (1), 65-78.

Dias, L.T., Leonel, M. (2006). Physicochemical characteristics of cassava flours from different regions of Brazil. Ciência e Agrotecnologia, 30 (4), 692-700.

Dongare, M. L., Buchade, P. B., Shaligram, A. D. (2015). Refractive index based optical Brix measurement technique. Optik, 126, 2383-2385.

Dubois, M., Gilles, K.A., Hamilton, J.K., Rebers, P.A., Smith, F. (1956). Colorimetric method from determination of sugars and related substances. Nature, 28 (3), 350-6.

Hemdane, S., Jacobs, P. J. J., Dornez, E., Verspreet, J., Delcour, J. A., Courtin, C. M. (2016). Wheat (Triticum aestivum L.) bran in bread making: a critical review. Comprehensive Reviews in Food Science and Food Safety, 15, 1-16.

Ishartani, D., Rahman, F. L. F., Hartanto, R., Utami, R., Khasanah, L. U. (2018). Physical, chemical and sensory characteristics of red guava (Psidium guajava) velva at different fruit ripening time. Earth and Environmental Science, 102, 1-9.

Koh, D., Park, J., Lim, J., Yea, M., Dae Bang, D. (2018). A rapid method for simultaneous quantification of 13 sugars 
and sugar alcohols in food products by UPLC-ELSD. Food Chemistry, 240, 694-700

Lane, J.H., Eynon, L. (1934). Determination of reducing sugars by Fehling's solution with methylene blue indicator. London: Normam Rodge.

Le, C., Stuckey, D. C. (2016). Colorimetric measurement of carbohydrates in biological wastewater treatment systems: A critical evaluation. Water Research, 94, 280-287

Marques, T. A., Rampazo, E. M., Zilliani, R. R., Marques, P. A. A., Benincasa, F. (2016). Automated sugar analysis. Food Science and Technology, 36(1), 70-75.

Matissek, R., Schnepel, F.M., Steiner, G. (1998). Analisis de los alimentos: Fundamentos, métodos, aplicaciones. (1st ed.). Zaragoza: Acribia.

McClements, J. (2014). Analysis of food products. Massachusetts: University of Massachusetts Amherst, UMass Amherst Information Technology. Available at: <http://people.umass.edu/ mcclemen/ 581Carbohydrates.html>. Accessed on: February 1, 2018.

Meade, G.P. (1967). Manual del azúcar de caña. (1st ed.). Barcelona: Montaner y Simon.

Miller, G.L. (1959). Use of dinitrosalicylic acid reagent for determination of reducing sugar. Analytical Chemistry, 31 (3), 426-8.

Morris, D.L. (1948). Quantitative determination of carbohydrates with dreywood's anthrone reagent. Science, 107 (5), 254-5.

NEPA. (2011). Tabela Brasileira de Composição de Alimentos. (4th ed.). Campinas: NEPA-UNICAMP.

Sá, A. C., Cipri, A., González-Calabuig, A., Stradiotto, N. R.,Valle, M. (2018). Multivariate Determination of Total Sugar Content and Ethanol in Bioethanol Production Using Carbon Electrodes
Modified with MWCNT/MeOOH and Chemometric Data Treatment. Electroanalysis, 30, 1696 - 1705.

Saidani, F., Giménez, R., Aubert, C., Chalot, G., Betrán, J. A., Gogorcen, Y. (2017). Phenolic, sugar and acid profiles and the antioxidant composition in the peel and pulp of peach fruits. Journal of Food Composition and Analysis, 62, 126-133

Silva, R.N., Monteiro, V.N., Alcanfor, J.D.X., Assis, E.M., Asquieri, E.R. (2003). Comparision methods for the determination of reducers sugars and total in honey. Food Science and Technology, 23 (3), 337-341.

Shao, Y., Lin, A. H. (2018). Improvement in the quantification of reducing sugars by miniaturizing the Somogyi-Nelson assay using a microtiter plate. Food Chemistry 240, 898-903.

Somogyi, M. (1945). A new reagent for the determination of sugars. The Jthisnal of Biological Chemistry, 160, 61-8.

Strazzi, S. (2015). Derivados do milho são usados em mais de 150 diferentes produtos industriais. Visão Agrícola, 13, 146-150.

Tavares, J.T.Q., Cardoso, R.L., Costa, J.A., Fadigas, F.S., Fonseca, A.A. (2010). Ascorbic acid interference in the determination of reducing and total sugars by Lane and Eynon method. Química Nova, 33 (4), 805-9.

Vicente, A.M. (1994). Métodos oficiales de analisis de los alimentos. (1st ed.). Madri: Mundi-Prensa.

Wang, Y., Jing, Y., Leng, F., Shiwei Wang, S., Wang, F., Zhuang, Y., Liu, X. F., Wang, X., Ma, X. (2017). Establishment and Application of a Method for Rapid Determination of Total Sugar Content Based on Colorimetric Microplate. Sugar Tech, 19(4), 424-431. 